Marquette University

e-Publications@Marquette

Exercise Science Faculty Research and

Publications

Exercise Science, Department of

Summer 2015

\title{
Using Group Model Building to Understand Factors That Influence Childhood Obesity in an Urban Environment
}

\author{
David A. Nelson \\ Medical College of Wisconsin \\ Christopher J. Simenz \\ Marquette University, christopher.simenz@marquette.edu \\ Sarah P. O'Connor \\ United Neighborhood Centers of Milwaukee \\ Yvonne Greer \\ Milwaukee Health Department \\ Ann L. Bachrach \\ Agape Community Center
}

See next page for additional authors

Follow this and additional works at: https://epublications.marquette.edu/exsci_fac

Part of the Public Health Commons

\section{Recommended Citation}

Nelson, David A.; Simenz, Christopher J.; O'Connor, Sarah P.; Greer, Yvonne; Bachrach, Ann L.; Shields, Tony; Fuller, Brett A.; Horrigan, Katie; Pritchard, Kathleen; Springer, Judy B.; and Meurer, John R., "Using Group Model Building to Understand Factors That Influence Childhood Obesity in an Urban Environment" (2015). Exercise Science Faculty Research and Publications. 83.

https://epublications.marquette.edu/exsci_fac/83 


\section{Authors}

David A. Nelson, Christopher J. Simenz, Sarah P. O'Connor, Yvonne Greer, Ann L. Bachrach, Tony Shields, Brett A. Fuller, Katie Horrigan, Kathleen Pritchard, Judy B. Springer, and John R. Meurer 


\title{
Using Group Model Building to Understand Factors That Influence Childhood Obesity in an Urban Environment
}

\author{
David A. Nelson \\ Family and Community Medicine, Medical College of Wisconsin \\ Milwaukee, WI \\ Christopher J. Simenz \\ Department of Physical Therapy-Program in Exercise Science, \\ Marquette University, \\ Milwaukee, WI \\ Sarah P. O'Connor \\ United Neighborhood Centers of Milwaukee, \\ Milwaukee, WI \\ Yvonne D. Greer \\ Y-Eat Right Consulting, \\ Milwaukee, WI \\ Ann L. Bachrach \\ Agape Community Center, \\ Milwaukee, WI
}


NOT THE PUBLISHED VERSION; this is the author's final, peer-reviewed manuscript. The published version may be accessed by following the link in the citation at the bottom of the page.

\author{
Tony Shields \\ United Neighborhood Centers of Milwaukee, \\ Milwaukee, WI \\ Brett A. Fuller \\ Wellness and Prevention Office, Milwaukee Public Schools, \\ Milwaukee, WI \\ Katie Horrigan \\ Children's Hospital of Wisconsin, \\ Milwaukee, WI \\ Kathleen Pritchard \\ IMPACT Planning Council, \\ Milwaukee, WI \\ Judy B. Springer \\ Physical Education, Milwaukee Area Technical College, \\ Milwaukee, WI \\ John R. Meurer \\ Institute for Health and Society, Medical College of Wisconsin \\ Milwaukee, WI
}

\begin{abstract}
Background: Despite increased attention, conventional views of obesity are based upon individual behaviors, and children and parents living with obesity are assumed to be the primary problem solvers. Instead of focusing exclusively on individual reduction behaviors for childhood obesity, greater focus should be placed on better understanding existing community systems and their effects on obesity. The Milwaukee Childhood Obesity Prevention Project is a community-based coalition established to develop policy and environmental change strategies to impact childhood obesity in Milwaukee, Wisconsin. The coalition conducted a Group Model Building exercise to better understand root causes of childhood obesity in its community.
\end{abstract}


NOT THE PUBLISHED VERSION; this is the author's final, peer-reviewed manuscript. The published version may be accessed by following the link in the citation at the bottom of the page.

Methods: Group Model Building is a process by which a group systematically engages in model construction to better understand the systems that are in place. It helps participants make their mental models explicit through a careful and consistent process to test assumptions. This process has 3 main components: (1) assembling a team of participants; (2) conducting a behavior-over-time graphs exercise; and (3) drawing the causal loop diagram exercise.

Results: The behavior-over-time graph portion produced 61 graphs in 10 categories. The causal loop diagram yielded 5 major themes and 7 subthemes.

Conclusions: Factors that influence childhood obesity are varied, and it is important to recognize that no single solution exists. The perspectives from this exercise provided a means to create a process for dialogue and commitment by stakeholders and partnerships to build capacity for change within the community.

Keywords: active living; childhood obesity; community engagement; healthy eating; social factors

Since first recognized as a "health hazard" $1, \underline{2}$ nearly 40 years ago, the prevalence of childhood obesity has continued to rise. $\frac{3}{}$ Despite increased attention, a conventional view of obesity is based upon individual behaviors, and children and parents living with obesity are assumed to be the primary problem solvers. $4, \underline{5}$ Instead of focusing only on individual reduction behaviors for childhood obesity, greater emphasis should be placed on understanding community systems and their effects on obesity. ${ }^{5}, \underline{6}$ A "systems thinking" approach represents methods, tools, and ways to observe the behavior of a system and how behaviors change over time. $\underline{7}$ Understanding the dynamics of nutrition and physical activity within families, neighborhood environments, and assets such as local coalitions and community centers, all hold promise for reducing childhood obesity without placing sole burden on the individual. $\underline{5}, \underline{6}, \underline{8}, \underline{9}$ The purpose of this article is to describe a community-academic partnership's effort to understand the community systems that influence childhood obesity in Milwaukee, Wisconsin.

Milwaukee is Wisconsin's largest and most racially and ethnically diverse city, with a population of nearly 600000.10 While Milwaukee's white population has declined, the number of African Americans, Hispanics, and Asians has increased. $\underline{11}$ Milwaukee is also a

Journal of Public Health Management and Practice, Vol 21, No. Supplement 3 (May/June 2015): pg. 574-578. DOI. This article is (C) Lippincott Williams \& Wilkins, Inc. and permission has been granted for this version to appear in ePublications@Marquette. Lippincott Williams \& Wilkins, Inc. does not grant permission for this article to be further copied/distributed or hosted elsewhere without the express permission from Lippincott Williams \& Wilkins, Inc.. 
city of contrasts. Although the city has the state's most concentrated health resources, health disparities are more pronounced than virtually all other areas of the state. $\underline{12, \underline{13}}$ As a result of existing disparities, there is a need for both focused and collaborative efforts to improve the health status for Milwaukee residents, with emphasis on neighborhoods where disparities are the greatest.

To serve the needs of neighborhoods and families within Milwaukee, the United Neighborhood Centers of Milwaukee $\underline{14}$ (UNCOM), a 501(c)(3) collaborative of 8 neighborhood settlement house agencies, Agape Community Center, COA Youth and Family Centers, Journey House, Milwaukee Christian Center, Neighborhood House of Milwaukee, Next Door Foundation, Northcott Neighborhood House, and Silver Spring Neighborhood Center, supports Milwaukee's most distressed neighborhoods. These agencies serve more than 63 000 residents annually at 24 sites, with more than 900 staff members, many of whom reside in the neighborhoods where they work. The agencies focus on lifelong health via preventive interventions, such as, meal and food programs, early childhood, afterschool and adult education, health education, population health improvement programs, and, in some cases, health clinics, in efforts to impact health disparities and issues impacted by poverty.

In 2008, the Robert Wood Johnson Foundation awarded UNCOM funds through its sponsored program, Healthy Kids, Healthy Communities (HKHC). HKHC is a national program of the Robert Wood Johnson Foundation, which funded 49 communities across the nation to implement healthy eating and active living policies. These policies focus on systems and environmental change strategies to support healthier communities for children and families, with special emphasis on reaching children at greatest risk for obesity based on race, ethnicity, income, or geographic location. $\frac{15}{}$ Active Living By Design served as the HKHC National Program Office and provided overall direction and technical assistance for the initiative, and Transtria, LLC, provided evaluation assistance for HKHC.

UNCOM's project, The Milwaukee Childhood Obesity Prevention Project (MCOPP), was built around a community-academic partnership and guided by the principles of community engagement in research. $\underline{16}$ MCOPP was based on a broad model of community change strategies rather than singular program implementation. The structure promoted 
open participation and included many external partners. Project partners consisted of more than 39 different community-based organizations, academic partners, and community members. MCOPP focused on policy and environmental change strategies at the UNCOM agencies within 4 areas: healthy food and beverages; active lifestyles; land use; and curriculum and professional development.

As a part of the project's evaluation, MCOPP partners participated in a Group Model Building (GMB) session designed by staff from Transtria, LLC, and the Social System Design Lab at Washington University. $\frac{17}{\mathrm{GMB}}$ is a process by which a group systematically engages in model construction and takes a systems approach to understand the root cause of an issue. It helps participants make their mental models explicit through a careful and consistent process to test assumptions. $\frac{18}{1}$ The GMB process is fully described elsewhere $\underline{17}$ but is built around 3 main steps: (1) assembling a team of participants; (2) conducting individual behaviorover-time graphs (BOTG) exercise; and (3) group drawing of the causal loop diagram (structural elicitation)ㄲe exercise. In this context, participants wanted to understand the root causes of childhood obesity to evaluate where MCOPP is making an impact.

\section{Methods}

\section{Group model building}

Twenty-six individuals representing community-based organizations, UNCOM staff, academic institutions, and community members participated in the 1 -day session. Within this process, both BOTG and the causal loop diagram in steps 2 and 3, respectively, were constructed around the statement, "Things that affect or are affected by policy, system, and environment changes in this community." 19 In step 2, individual participants drew graphs of how features of the system that affects childhood obesity have changed from the past to their current state and describe what may occur in the future. Using an iterative process, all participants of the session first discussed and then physically grouped the created BOTG into similar categories. Themes that emerged from the BOTG were noted and provided insights into the local context. Step 3, the causal loop diagram exercise, featured a view of the "holistic system" and 
subsystems that influence childhood obesity in Milwaukee. Participants examined the relationships between the variables from the BOTG and identified new variables from groups of graphs that either increase or decrease over time depending on the influence. Lines connected variables and arrows indicated either a positive or negative influence on that variable. The lines represented causal relationships and demonstrate what is known about the system, the interactions therein, and how the system behaves. ${ }^{?}$

\section{Results}

The BOTG portion produced 61 graphs in 10 categories. The causal loop diagram yielded 5 major themes and 7 subthemes. The Table provides details on the concepts developed through the first of the 3-step process. Selected verbatim comments provide context to the session.

Availability of Junk Food: "On any given day that I'm in a school or community center I see at least one form of junk food, if not more, held by a child of any age."

Family Involvement: "Our goal is to decrease childhood obesity, but in order to decrease childhood obesity, we first have to have family involvement."

\section{Discussion}

Factors that influence childhood obesity are varied, and it is important to recognize that no single solution exists and that a variety of structural changes, policies, and community-based interventions are needed. $.20,21$ The perspectives from this exercise provide a means to create a process for dialogue and commitment by stakeholders and partnerships to build capacity for change within the community. A number of lessons learned in the following areas emerged from the GMB activity: (1) the complexity of obesity is best explained via multiple perspectives; (2) an asset-based perspective with an orientation to the future is needed to solve this issue; and (3) to maximize impact over time, policies and environmental change strategies are needed.

First, childhood obesity is a complex and multifocal issue not easily understood, nor explained by the individual measurement of 
body mass index. Instead, taking a systems thinking approach allowed us to examine the conditions that either prevent or facilitate obesity through multiple perspectives. These perspectives not only include "professionals" from academic institutions and health care, but also include perspectives from community members and community-based organizations to gain the greatest sense of the issues at hand. Broad community participation not only provided a different perspective but also provides a basis for lasting change. In this context, the community perspective aligned with the goals of MCOPP.

Next, not only is it important to think of childhood obesity from an orientation of multiple perspectives but a framework is needed as well. Community engagement in research provided such a framework, and through this perspective, community-academic partnerships share ideas, learn from each other, and focus on the assets within the community as opposed to pointing out the deficits. A good example of this asset-based approach was demonstrated in the BOTG that were created by the participants. A common feature of almost all the graphs was an optimistic outlook of participants toward healthy eating and active living. Despite challenges, the graphs indicated an orientation toward improvement in areas that would eventually result in a reduction of childhood obesity. Said one participant to reflect this optimism, "I would say there is greater collaboration and as the collaboration involves more and more different people, then that in turn will affect it and more families will become involved."

Finally, to facilitate change within the community, communitybased organizations need to create policies and environmental change strategies that support the areas of healthy eating and active living as outlined in the causal loop diagram (Figure). Such strategies provide the basis for influence at a much greater level than individual efforts that promote healthy eating and active living. For example, the UNCOM agencies through MCOPP developed and adopted model policies for their community centers in the areas of healthy food and beverages; active lifestyles; land use; and curriculum and professional development. These policies provided a structural framework that can be adopted and adapted by each of the 8 agencies depending on the cultural norms and standards that exist at each agency. Taken collectively, over time, these policies not only 
influence individual behaviors of those who utilize the agency but also provide a structure of influence for the community.

Despite the optimism expressed in the graphs, it remains essential to acknowledge and address the social determinants of health present in these communities, which include perceptions of neighborhood safety, healthy food availability, parental engagement, and the availability of processed food as signified in at least one of the quotes. The root of this complexity is based upon economic disorder, housing conditions, lack of grocery stores, and other interactions with the environment that impede healthy eating and active living. Despite these determinants, community-based organizations such as the UNCOM agencies, professionals, academics, and community members provided a level of understanding that is not evident when one views obesity from the singular feature of weight status. Taking systems thinking into account and performing exercises such as GMB let everyone involved know that they were on the right path for lasting change.

\section{References}

${ }^{1}$ Charney E, Goodman HC, McBride M, Lyon B, Pratt R. Childhood antecedents of adult obesity. N Engl J Med. 1976;295(1):6-9.

2 Editorial: infant and adult obesity. Lancet. 1974;1(7845):17-18.

${ }^{3}$ Ebbeling CB, Pawlak DB, Ludwig DS. Childhood obesity: public-health crisis, common sense cure. Lancet. 2002;360(9331):473-482.

${ }^{4}$ Lawrence R. Framing obesity: the evolution of new discourse on a public health issue. Int J Press/Polit. 2004;9(3):56-75.

${ }^{5}$ Schwartz MB, Puhl R. Childhood obesity: a societal problem to solve. Obes Rev. 2003;4:57-71.

${ }^{6}$ Committee on Prevention of Obesity in Children and Youth, Food and Nutrition Board, Board on Health Promotion and Disease Prevention. Preventing Childhood Obesity: Health in the Balance. Washington, DC: Institute of Medicine; 2005.

7 Brennan L, Sabounchi N, Behlmann T, Nelson D, O'Connor S. Systems thinking in communities: understanding the causes of inactivity, poor diet/nutrition, and childhood obesity in Milwaukee, Wisconsin. http://www.transtria.com/hkhc. Published 2013. Accessed November $18,2014$. 
NOT THE PUBLISHED VERSION; this is the author's final, peer-reviewed manuscript. The published version may be accessed by following the link in the citation at the bottom of the page.

${ }^{8}$ Council on Sports Medicine and Fitness; Council on School Health. Active healthy living: prevention of childhood obesity through increased physical activity. Pediatrics. 2006;117(5):1834-1842.

${ }^{9}$ A growing problem: what causes childhood obesity? http://www.cdc.gov/obesity/childhood/problem.html. Accessed March 4, 2014.

10 US Census Bureau. State and County QuickFacts. quickfacts.census.gov/gfd/states/55/55031.html. Accessed March 6, 2012.

${ }^{11}$ Milwaukee Comprehensive Plan-Citywide Policy Plan. Milwaukee, WI: Department of City Development; March; 2010.

${ }^{12}$ City of Milwaukee Health Department Planning and Policy Recommendations: As a Result of the Mobilizing Action Through Planning and Partnerships (MAPP) Strategic Planning Process. Milwaukee, WI: City of Milwaukee Health Department; 2010.

${ }^{13}$ County Health Rankings 2011. http://www.countyhealthrankings.org/wisconsin/milwaukee. Accessed March 29, 2012.

${ }^{14}$ United Neighborhood Centers of Milwaukee. https://www.uncommilw.org/login.asp. Accessed March 5, 2014.

${ }^{15}$ Healthy Kids, Healthy Communities: Supporting Community Action to Prevent Childhood Obesity. http://www.healthykidshealthycommunities.org/communities. Published 2014. Accessed March 5, 2014.

${ }^{16}$ Minkler M, Wallerstein N. Introduction to Community Based Participatory Research. San Francisco, CA: Jossey-Bass; 2003.

17 Healthy Kids, Healthy Communities Group Model Building Facilitation Handbook. St Louis, MO: Transtria LLC and the Social System Design Lab at Washington University in St Louis; 2013.

18 Vennix JAM. Group model-building: tackling messy problems. Syst Dyn Rev. 1999;15:379-401.

19 Hovmand P, Brennan L, Kemner A. Healthy kids, Healthy Communities group model building facilitation handbook. http://www.transtria.com/hkhc. Published 2013. Accessed May 19, 2014

${ }^{20}$ Gortmaker SL, Swinburn BA, Levy D, et al. Changing the future of obesity: science, policy, and action. Lancet. 2011;378(9793):838-847.

${ }^{21}$ Population-Based Approaches to Childhood Obesity Prevention. Geneva, Switzerland: World Health Organization; 2012. 
NOT THE PUBLISHED VERSION; this is the author's final, peer-reviewed manuscript. The published version may be accessed by following the link in the citation at the bottom of the page.

This study was funded through The Robert Wood Johnson Foundation contract \#66792. The authors are grateful for the assistance of Fay Gibson of Healthy Kids, Healthy Communities, the Robert Wood Johnson Foundation, and Tammy Behlmann of Transtria, LLC, for their support and direction throughout the project.

The authors declare no conflicts of interest.

Correspondence: David A. Nelson, PhD, MS, Family and Community Medicine, Medical College of Wisconsin, 8701 Watertown Plank Rd, Milwaukee, WI 53226 (danelson@mcw.edu). 